\title{
Muscular function and functional mobility of faller and non-faller elderly women with osteoarthritis of the knee
}

\author{
M.A. Alencar, \\ P.M.M. Arantes,
}

J.M.D. Dias, R.N. Kirkwood, L.S.M. Pereira and R.C. Dias

\author{
Departamento de Fisioterapia, Escola de Educação Física, \\ Fisioterapia e Terapia Ocupacional, Universidade Federal de Minas Gerais, \\ Belo Horizonte, MG, Brasil
}



Received March 3, 2006 Accepted October 9, 2006

\begin{abstract}
Falls are a major concern in the elderly population with chronic joint disease. To compare muscular function and functional mobility among older women with knee osteoarthritis with and without a history of falls, 15 elderly women with a history of falls $(74.20 \pm 4.46$ years) and 15 without a history of falls $(71.73 \pm 4.73$ years $)$ were studied. Muscular function, at the angular speed of 60,120 , and $180^{\circ} / \mathrm{s}$, was evaluated using the Biodex Isokinetic Dynamometer. The sit-to-stand task was performed using the Balance Master System and the Timed Up and Go test was used to determine functional mobility. After collection of these data, the history of falls was investigated. A statistically significant difference was detected in the time taken to transfer the center of gravity during the sit-to-stand test (means $\pm \mathrm{SD}$; non-fallers: $0.35 \pm 0.16 \mathrm{~s}$; fallers: $0.55 \pm 0.32 \mathrm{~s} ; \mathrm{P}=0.049$, Student $t$ test) and in the Timed Up and Go test (medians; non-fallers: $10.08 \mathrm{~s}$; fallers: $11.59 \mathrm{~s} ; \mathrm{P}=0.038$, Mann-Whitney U-test). The results indicated that elderly osteoarthritic women with a history of falls presented altered functional mobility and needed more time to transfer the center of gravity in the sit-to-stand test. It is important to implement strategies to guarantee a better functional performance of elderly patients to reduce fall risks.
\end{abstract}

\section{Introduction}

A clear process of demographic aging has been observed over the last decades. In this scenario, Brazil stands out by presenting one of the largest growth rates of the aging population, reaching about $10 \%$ in the 2000 decade (1).

The aging process is accompanied by changes in the musculoskeletal system such as sarcopenia and by compromised muscular
Key words

- Elderly women

- Falls

- Knee osteoarthritis

- Muscular function

- Functional performance function (2). These declines have been correlated with a decreased capacity of accomplishing activities of daily living (ADLs) (2).

Chronic-degenerative diseases can manifest in association with the changes that occur with the aging process (3). Osteoarthritis $(\mathrm{OA})$ is the most prevalent chronic degenerative joint disease in the elderly population (4). The main signs and clinical symptoms of this disease are pain, edema, stiffness, and articular instability (5). When OA affects 
weight-bearing joints, mainly the knee, it leads to a marked decline of muscle function and consequently to a reduction of balance and especially of the ability to perform sitto-stand tasks, to gait alterations, functional limitation, and loss of independence $(6,7)$. Therefore, OA is considered to be an intrinsic risk factor for the occurrence of falls (8).

Falls constitute one of the major public health concerns. They frequently have a negative impact on the life of elderly women and could lead to an increase of dependence, fear of new falls, fractures, institutionalization, and death (8). The detection of factors possibly associated with falls may allow professionals to implement a secondary preventive intervention of great importance due to the fact that suffering a first fall increases the risk of a second fall (8).

The study of falls in patients with OA is essential, given the fact that these elderly women are more inclined to fall. Both OA and falls generate a significant burden for health services (8).

Literature data correlating OA and falls in the elderly are scarce. Therefore, the purpose of the present study was to compare muscle function and functional mobility between faller and non-faller elderly women with knee OA.

\section{Material and Methods}

\section{Subjects}

This was a cross-sectional study of a sample composed of 15 elderly women with a history of falls and 15 elderly women with no history of recent falls. The communitydwelling volunteers were recruited from different social senior groups and from the University Hospital Outpatient Clinic. The inclusion criteria were: age of 65 years or more, clinical and radiographic diagnosis of bilateral knee OA based on the criteria of the American Association of Rheumatism (9) and the ability to walk at least $20 \mathrm{~m}$ without any aid. Exclusion criteria were the presence of another concomitant musculoskeletal disease, the presence of neurological diseases, history of hip or knee surgeries, and the presence of cognitive deficits assessed by the Mini-Mental State Examination (10).

\section{Instruments}

Before starting data collection a pilot study was conducted to establish intra-rater reliability of all measurements which yielded moderate to high (0.70) intra-class correlation coefficients.

The isokinetic dynamometer Biodex System 3 Pro (Biodex Medical System, Shirley, NY, USA) was used to evaluate muscle function. The isokinetic dynamometer is an electromechanical instrument controlled by a microcomputer, which offers the possibility of objectively and quantitatively evaluating physical parameters of the muscle function such as strength, power and resistance in different joints during different angular velocities (11).

Performance during the sit-to-stand task (STS) was evaluated using the Balance Master (NeuroCom ${ }^{\circledR}$ System, NeuroCom International, Inc., Clackamas, OR, USA). This instrument has two adjacent force platforms connected to a microcomputer which are capable of detecting the center of gravity (CG) sway during different tasks $(12,13)$. The equipment provides quantitative data through balance tests that reproduce ADLs (12). The STS test is significantly correlated with the Performance Oriented Mobility Assessment scale and with functional measures of gait (14).

The Timed Up and Go (TUG) test was used to evaluate the functional mobility of the participants. The TUG is a test of easy and quick application that does not require special equipment and that could be easily included as part of the routine evaluation of elderly individuals (15). The TUG test measures in seconds the time taken by an indi- 
vidual to get up from a chair, walk a distance of $3 \mathrm{~m}$, turn $180^{\circ}$ and return to the chair, sitting down again (15). The chair used for the test was armless, $44 \mathrm{~cm}$ high and had a $20^{\circ}$ angle of inclination of the backrest. This test has a concurrent validity of moderate to high when correlated with gait speed $(\mathrm{r}=$ $-0.61)$ and with the Berg Balance Scale ( $r=$ -0.81 ), as well as content validity (15).

In order to evaluate knee pain a visual analog scale of $10 \mathrm{~cm}$, with a mark indicating "no pain" at one end and a mark indicating "unbearable pain" at the other, was used prior to testing. The participant was asked to mark the amount of pain felt at the time of evaluation.

\section{Procedure}

After approval of the project by the Ethics Committee of the Federal University of Minas Gerais (UFMG), Belo Horizonte, MG, Brazil, the selected individuals received a detailed explanation about the procedures of the study and signed a consent form to participate. Data were collected on two nonconsecutive days in order to avoid muscle fatigue, at the Laboratory of Motor and Functional Human Performance, Physical Therapy Department, School of Physical Education, Physical Therapy and Occupational Therapy, UFMG. Demographic and clinical aspects such as age, body mass, body mass index, number of co-morbidities, number of drugs in use, and amount of pain felt on the side of the body more or less affected were obtained for each group. The most affected limb was determined on the basis of the participant's self-report based on knee pain and discomfort.

For the isokinetic evaluation, the individuals were positioned in the dynamometer, sitting with the trunk, pelvis and thigh stabilized by belts. The less affected lower limb was evaluated first. The back of the chair was inclined at an $85^{\circ}$ angle and the rotational axis of the device was aligned with the rotational axis of the knee joint, at the level of the lateral epicondyle of the femur. The lever arm was positioned parallel to the leg, with the support cushion fastened immediately above the lateral malleolus. The test was performed in a total range of motion of $85^{\circ}$, starting at a $90^{\circ}$-angle flexion of the knee. According to the manufacturer's instructions the mass of the lower limb to be tested was measured so that gravity correction could be guaranteed. This measurement was made with the knee at $5^{\circ}$ of flexion.

Muscle performance was evaluated bilaterally at angular velocities of 60,120 , and $180^{\circ}$ s during concentric quadriceps and hamstring contractions. To assure familiarization with the procedures of the test, 3,4 , and 5 repetitions were performed in a submaximum effort at speeds of 60,120, and 180/s, respectively. The test consisted of 5 repetitions at $60 \%$ s, 10 at $120 \%$, and 15 at $180 \%$ s. There was a 30-s interval between the velocities tested. During evaluation, the volunteers were verbally stimulated to move the lever of the dynamometer as fast and as powerfully as possible, trying to produce a maximum torque. Any complaints reported by the participant were taken into account and, if necessary, the test was stopped.

The test in the Balance Master was done with the participants barefoot, to eliminate the effects of shoe use (16). The individuals sat on a bench according to manufacturer instructions, with the arms resting by the sides. They were requested to stand up as quickly as possible without the help of the upper limbs or any other physical aid. A familiarization trial and consisting of three repetitions of the task was performed.

The participants were instructed not to use their arms to get up and to walk as quickly as possible, but in a safe way in the TUG test (17). The participants walked barefoot to eliminate the effects of shoes (16) and no physical help was given. First, a familiarization test took place. Soon afterwards, two timed tests were performed and the final 
result was calculated as the mean of these two times (18).

At the end of the evaluations, information on the history of falls, such as whether or not she had fallen in the last 6 months, the number of falls, if she was afraid of falling, and if she had stopped performing any activity due to the fear of falling, was collected. A fall was defined as a non-intentional event that results in the shift of the individual's posture to a lower level in regard to his/her initial posture $(17,18)$. The participants were divided into two groups according to the following criteria: occurrence or not of fall(s) in the last 6 months.

\section{Data analysis}

Isokinetic dynamometer variables. The value of the peak torque by body mass ratio was obtained by the highest point of a series of torque curves $(\mathrm{Nm})$. The work is the area below the torque curve (Joules). The mean power by body mass ratio is the product of the momentum of force by the angular velocity (Watts). All of these variables were normalized for body mass $(\mathrm{kg})$ and the values were multiplied by 100 (11).

STS test (Balance Master) variables. Transfer time is the time between the begin-

Table 1. Demographic and clinical variables of women non-fallers and fallers.

\begin{tabular}{lcc}
\hline & Non-fallers & Fallers \\
\hline Age (years) & $71.73 \pm 4.73$ & $74.20 \pm 4.46$ \\
Body mass $(\mathrm{kg})$ & $73.01 \pm 10.61$ & $72.38 \pm 12.14$ \\
BMI (kg/m²) & $31.04 \pm 3.80$ & $30.60 \pm 4.84$ \\
Co-morbidities & $2.80 \pm 1.01$ & $2.50 \pm 1.77$ \\
Number of medicines & $3.20 \pm 2.34$ & $3.40 \pm 1.84$ \\
Pain (VAS) & $7.04 \pm 2.53$ & $6.31 \pm 2.53$ \\
More affected side & $3.33 \pm 1.44$ & $3.75 \pm 3.14$ \\
Less affected side & $10(66.67 \%)$ & $14(93.3 \%)$ \\
Fear of falling $(\mathrm{N})$ & $7(46.67 \%)$ & $9(60.0 \%)$ \\
Stopped activity due to & & \\
$\quad$ fear of falling & \\
\hline
\end{tabular}

Data are reported as means \pm SD for 15 women in each group. BMI = body mass index; VAS = visual analog scale. There were no statistical differences between groups (Student $t$-test and aMann-Whitney U-test). ning of the movement and the arrival of the CG above the feet; elevation index is the amount of force, as percentage of body weight, exerted by the body during the getting up phase and the speed of CG balancing is the sway of CG from getting up to the first $5 \mathrm{~s}$ of the stand up posture $(18,19)$.

\section{Statistical analysis}

Data were analyzed statistically using the SPSS program for Windows, version 10.0. Descriptive statistics of all the variables were reported. Normality of the data was tested by the Kolmogorov-Smirnov test. For the comparison between the two groups the Student $t$-test for independent samples or the Mann-Whitney U-test was used according to data distribution. The level of significance for the variables analyzed with the isokinetic dynamometer was established at $\alpha<0.017$, according to the Bonferroni correction used to adjust the level of significance to the number of comparisons made (20). For the other variables analyzed, the level of significance was set at $\alpha<0.05$.

\section{Results}

There were no statistically significant differences between the two groups when the demographic and clinical variables were compared (Table 1). Most of the participants who had fallen were recurrent fallers. The mean number of falls for this group was 2.2 \pm 1.70 falls in the last 6 months.

Analysis of the fall questionnaire showed no significant difference between groups regarding fear of falling or the reduction of the number of activities performed due to the fear of falling (Table 1).

There were no statistically significant differences between groups in the three speeds tested for peak torque, work and power values of the knee extensors and flexors of the more affected limb. However, participants who fell tended to have wors- 
ened muscle function. Also, there were no statistically significant differences when muscle function was compared between the more and less affected limb in the two groups.

Amongst the variables of the STS test, the CG transfer time was the only one that presented a statistically significant difference $(P=0.049)$. Regarding sway speed, a tendency contrary to the expected one was observed. The participants without a history of falls presented larger sway (Table 2).

Fallers presented a statistically worse performance in functional mobility, measured by the TUG test, when compared to non-fallers $(10.22 \pm 2.27$ vs $13.65 \pm 5.94 \mathrm{~s} ; \mathrm{P}$ $=0.038$ ).

\section{Discussion}

The purpose of the present study was to compare muscle function and functional mobility between faller and non-faller elderly women with knee OA. These outcomes are very relevant for daily life activities, especially in order to maintain independence and autonomy.

There were no statistically significant differences $(\mathrm{P}>0.05)$ between the two groups regarding demographic and clinical variables.

In the present study, the severity of OA was not evaluated radiographically since other studies have established that there is no correlation between radiographic and clinical functional findings $(21,22)$.

A statistically significant difference was observed between the two groups for the time of the TUG test. The participants with a history of falls spent more time performing the test. Since the TUG test provides information about transfer, balance and gait speed (15), this finding confirms the fact that elderly women who have a history of falls have more difficulty in accomplishing functional tasks related to mobility and transferring or are more careful when performing them. The average time measured in this study, $10.22 \mathrm{~s}$ for the group without a history of falls in the last 6 months and $13.65 \mathrm{~s}$ for the group with a history of falls, agrees with the cut-off points (>13.5 s) proposed (17) for risk of falls. Comparisons with other studies could not be made due to some methodological differences between studies $(15,18)$, such as different chair heights, and different samples (16). A standardization of the procedures of all variables that influence the execution of the test, such as the command given to the individual, the height and depth of the chair, whether or not the use of the upper limbs was allowed, and if shoes were used or not, is necessary for comparisons among studies.

In the present study, the group with a history of falls was slower in transferring the CG during the sit-to-stand movement. Slowing the movement is necessary to control the CG and to maintain a better postural stability. In addition, the control of CG is important to the performance of the movement, given the fact that if the CG is moved forward excessively or not enough, a fall forward or back to the seat could occur, respectively (19).

The speed of the sit-to-stand movement influences the vertical component of the CG. Faster movements lead to a greater oscillation of this center. Pain due to knee OA might lead individuals to transfer from a sitting to a standing position in a more cautious manner, increasing the time to do the task. This suggests that there might be an underlying dysfunction which can result in a decline in physical functioning and falls $(23,24)$.

Pain associated with knee OA may play a

Table 2. Comparison of sit-to-stand variables (Balance Master) between women non-fallers and fallers.

\begin{tabular}{lrr}
\hline Sit-to-stand variables & Non-fallers & \multicolumn{1}{c}{ Fallers } \\
\hline Time of transfer (s) & $0.35 \pm 0.16$ & $0.55 \pm 0.32^{*}$ \\
Index of elevation (\% body weight) & $19.33 \pm 8.17$ & $16.46 \pm 7.89$ \\
Sway speed $(\%)$ & $4.97 \pm 0.89$ & $4.21 \pm 1.24$
\end{tabular}

Data are reported as means \pm SD for 15 women in each group. ${ }^{*} \mathrm{P}<0.05$ compared to non-fallers (Student $t$-test). 
role in sway increases. Hassan et al. (25) found knee pain to be a significant predictor of sway in individuals with knee OA. Moreover, there is evidence of a direct association between severity of knee pain and postural sway $(6,26)$. Possibly, pain might generate a reflex inhibition of knee muscles which yields an ineffective and imprecise response related to postural control (25). Furthermore, knee pain could results in lower weight bearing by the affected joint, preventing the ability of a person with OA to maintain the center of mass inside the base of support (27).

The results of the present study suggest that elderly women with knee OA associated with history of falls present worse performance in functional mobility and require a longer period of time to transfer the CG during a balance test when compared to a similar group without a history of falls. Another important aspect to be considered is the elevated rate of occurrence of fear of falling in both groups, probably as a consequence of OA.

Thus, it is important that proper strategies be implemented to assure an improved functional and balance performance of these elderly women, which may result in a higher level of confidence regarding the performance of daily tasks, in order to reduce the risk of falls.

\section{References}

1. Siqueira RL, Botelho MIV, Coelho FMG. A velhice: algumas considerações teóricas e conceituais. Ciência Saúde Coletiva 2002; 7: 899-906.

2. Ploutz-Snyder LL, Manini T, Ploutz-Snyder RJ, Wolf DA. Functionally relevant thresholds of quadriceps femoris strength. $J$ Gerontol $A$ Biol Sci Med Sci 2002; 57: B144-B152.

3. Huang $M H$, Lin YS, Yang RC, Lee CL. A comparison of various therapeutic exercises on the functional status of patients with knee osteoarthritis. Semin Arthritis Rheum 2003; 32: 398-406.

4. Slemenda CW. The epidemiology of osteoarthritis of the knee. Curr Opin Rheumatol 1992; 4: 546-551.

5. Dieppe PA, Lohmander LS. Pathogenesis and management of pain in osteoarthritis. Lancet 2005; 365: 965-973.

6. Hinman RS, Bennell KL, Metcalf BR, Crossley KM. Balance impairments in individuals with symptomatic knee osteoarthritis: a comparison with matched controls using clinical tests. Rheumatology 2002; 41: 1388-1394.

7. Pandya NK, Draganich LF, Mauer A, Piotrowski GA, Pottenger L. Osteoarthritis of the knees increases the propensity to trip on an obstacle. Clin Orthop Relat Res 2005; 431: 150-156.

8. Tinetti ME, Speechley M. The effect of falls and fall injuries on functioning in community-dwelling older persons. J Gerontol 1998; 53: $112-119$.

9. Altman RD. The classification of osteoarthritis. J Rheumatol Suppl 1995; 43: 42-43.

10. Brucki SM, Nitrini R, Caramelli P, Bertolucci PH, Okamoto IH. Suggestions for utilization of the Mini-Mental State Examination in Brazil. Arq Neuropsiquiatr 2003; 61: 777-781.

11. Perrin DH. Interpreting an isokinetic evaluation. In: Perrin DH (Editor), Isokinetic exercise and assessment. UK: Human Kinetics Publishers; 1993.

12. Topp R, Mikesky A, Thompson K. Determinants of four functional tasks among older adults: an exploratory regression analysis. $J$
Orthop Sports Phys Ther 1998; 27: 144-153.

13. Davies J, Fernando R, McLeod A, Verma S, Found P. Postural stability following ambulatory regional analgesia for labor. Anesthesiology 2002; 97: 1576-1581.

14. Camicioli R, Panzer VP, Kaye J. Balance in the healthy elderly: posturography and clinical assessment. Arch Neurol 1997; 54: 976981.

15. Podsiadlo D, Richardson S. The Timed "Up \& Go": a test of basic functional mobility for frail elderly persons. J Am Geriatr Soc 1991; 39: $142-148$.

16. Janssen WG, Bussmann HB, Stam HJ. Determinants of the sit-tostand movement: a review. Phys Ther 2002; 82: 866-879.

17. Shumway-Cook A, Brauer S, Woollacott M. Predicting the probability for falls in community-dwelling older adults using the Timed Up \& Go Test. Phys Ther 2000; 80: 896-903.

18. Boulgarides LK, McGinty SM, Willett JA, Barnes CW. Use of clinical and impairment-based tests to predict falls by community-dwelling older adults. Phys Ther 2003; 83: 328-339.

19. NeuroCom International, Inc. Balance master operators manual. Version 7.0. Clackamas; 1999.

20. Ottenbacher KJ. Statistical conclusion validity. Multiple inferences in rehabilitation research. Am J Phys Med Rehabil 1991; 70: 317322.

21. Link TM, Steinbach LS, Ghosh S, Ries M, Lu Y, Lane N, et al. Osteoarthritis: MR imaging findings in different stages of disease and correlation with clinical findings. Radiology 2003; 226: 373-381.

22. Foley SJ, Lord SR, Srikanth V, Cooley H, Jones G. Falls risk is associated with pain and dysfunction but not radiographic osteoarthritis in older adults: Tasmanian Older Adult Cohort study. Osteoarthr Cartil 2006; 14: 533-539.

23. Faria JC, Dias RC, Machala CC, Alencar MA, Arantes PMM, Dias JMD. Transferência da posição sentada para em pé: estudo comparativo entre idosas assintomáticas e idosas com osteoartrite e 
correlação entre tempo da tarefa e função muscular. Rev Bras Fisioterap 2005; 9: 249-255.

24. Pai YC, Rogers MW. Speed variation and resultant joint torques during sit-to-stand. Arch Phys Med Rehabil 1991; 72: 881-885.

25. Hassan BS, Mockett S, Doherty M. Static postural sway, proprioception, and maximal voluntary quadriceps contraction in patients with knee osteoarthritis and normal control subjects. Ann Rheum Dis 2001; 60: 612-618.
26. Hall MC, Mockett SP, Doherty M. Relative impact of radiographic osteoarthritis and pain on quadriceps strength, proprioception, static postural sway and lower limb function. Ann Rheum Dis 2006; 65: 865-870.

27. Hurwitz DE, Ryals AR, Block JA, Sharma L, Schnitzer TJ, Andriacchi TP. Knee pain and joint loading in subjects with osteoarthritis of the knee. J Orthop Res 2000; 18: 572-579. 